NASA/TM-2003-211972

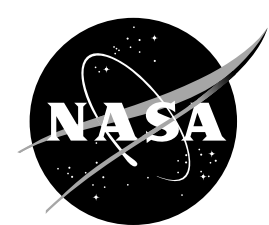

\title{
Performance Enhancement of Tunable Bandpass Filters Using Selective Etched Ferroelectric Thin Films
}

Félix A. Miranda

Glenn Research Center, Cleveland, Ohio

Carl H. Mueller

Analex Corporation, Brook Park, Ohio

Fred W. Van Keuls

Ohio Aerospace Institute, Brook Park, Ohio

Guru Subramanyam and Sivaruban Vignesparamoorthy University of Dayton, Dayton, Ohio 
Since its founding, NASA has been dedicated to the advancement of aeronautics and space science. The NASA Scientific and Technical Information (STI) Program Office plays a key part in helping NASA maintain this important role.

The NASA STI Program Office is operated by Langley Research Center, the Lead Center for NASA's scientific and technical information. The NASA STI Program Office provides access to the NASA STI Database, the largest collection of aeronautical and space science STI in the world. The Program Office is also NASA's institutional mechanism for disseminating the results of its research and development activities. These results are published by NASA in the NASA STI Report Series, which includes the following report types:

- $\quad$ TECHNICAL PUBLICATION. Reports of completed research or a major significant phase of research that present the results of NASA programs and include extensive data or theoretical analysis. Includes compilations of significant scientific and technical data and information deemed to be of continuing reference value. NASA's counterpart of peerreviewed formal professional papers but has less stringent limitations on manuscript length and extent of graphic presentations.

- TECHNICAL MEMORANDUM. Scientific and technical findings that are preliminary or of specialized interest, e.g., quick release reports, working papers, and bibliographies that contain minimal annotation. Does not contain extensive analysis.

- CONTRACTOR REPORT. Scientific and technical findings by NASA-sponsored contractors and grantees.
- CONFERENCE PUBLICATION. Collected papers from scientific and technical conferences, symposia, seminars, or other meetings sponsored or cosponsored by NASA.

- SPECIAL PUBLICATION. Scientific, technical, or historical information from NASA programs, projects, and missions, often concerned with subjects having substantial public interest.

- TECHNICAL TRANSLATION. Englishlanguage translations of foreign scientific and technical material pertinent to NASA's mission.

Specialized services that complement the STI Program Office's diverse offerings include creating custom thesauri, building customized databases, organizing and publishing research results ... even providing videos.

For more information about the NASA STI Program Office, see the following:

- Access the NASA STI Program Home Page at http://www.sti.nasa.gov

- E-mail your question via the Internet to help@sti.nasa.gov

- Fax your question to the NASA Access Help Desk at 301-621-0134

- Telephone the NASA Access Help Desk at 301-621-0390

- Write to:

NASA Access Help Desk

NASA Center for AeroSpace Information 7121 Standard Drive

Hanover, MD 21076 
NASA/TM-2003-211972

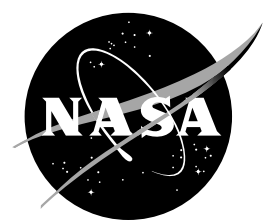

\section{Performance Enhancement of Tunable Bandpass Filters Using Selective Etched Ferroelectric Thin Films}

Félix A. Miranda

Glenn Research Center, Cleveland, Ohio

Carl H. Mueller

Analex Corporation, Brook Park, Ohio

Fred W. Van Keuls

Ohio Aerospace Institute, Brook Park, Ohio

Guru Subramanyam and Sivaruban Vignesparamoorthy University of Dayton, Dayton, Ohio

Prepared for the

13th International Symposium on the Applications of Ferroelectrics

sponsored by the Ultrasonics, Ferroelectrics, and Frequency Control Society

Nara, Japan, May 28-June 1, 2002

National Aeronautics and

Space Administration

Glenn Research Center 
Available from

NASA Center for Aerospace Information 7121 Standard Drive

Hanover, MD 21076
National Technical Information Service 5285 Port Royal Road Springfield, VA 22100

Available electronically at http://gltrs.grc.nasa.gov 


\title{
PERFORMANCE ENHANCEMENT OF TUNABLE BANDPASS FILTERS USING SELECTIVE ETCHED FERROELECTRIC THIN FILMS
}

\author{
Félix A. Miranda \\ National Aeronautics and Space Administration \\ Glenn Research Center \\ Cleveland, Ohio 44135 \\ Carl H. Mueller \\ Analex Corporation \\ Brook Park, Ohio 44142 \\ Fred W. Van Keuls \\ Ohio Aerospace Institute \\ Brook Park, Ohio 44142 \\ Guru Subramanyam and Sivaruban Vignesparamoorthy \\ Department of Electrical and Computer Engineering \\ University of Dayton \\ Dayton, Ohio 45458
}

\begin{abstract}
The inclusion of voltage-tunable barium strontium titanate (BSTO) thin films into planar band pass filters offers tremendous potential to increase their versatility. The ability to tune the passband so as to correct for minor deviations in manufacturing tolerances, or to completely reconfigure the operating frequencies of a microwave communication system, are highly sought-after goals. However, use of ferroelectric films in these devices results in higher dielectric losses, which in turn increase the insertion loss and decrease the quality factors of the filters. This study explores the use of patterned ferroelectric layers to minimize dielectric losses without degrading tunability. Patterning the ferroelectric layers enables us to constrict the width of the ferroelectric layers between the coupled microstrip lines, and minimize losses due to ferroelectric layers. Coupled one-pole microstrip bandpass filters with fundamental resonances at $\sim 7.2 \mathrm{GHz}$ and well-defined harmonic resonances at $\sim 14.4$ and $\sim 21.6 \mathrm{GHz}$, were designed, simulated and tested. For one of the filters, experimental results verified that its center frequency was tunable by $528 \mathrm{MHz}$ at a center frequency of $21.957 \mathrm{GHz}$, with insertion losses varying from 4.3 to $2.5 \mathrm{~dB}$, at 0 and $3.5 \mathrm{~V} / \mu \mathrm{m}$, respectively. These data demonstrate that the tuning-to-loss figure of merit of tunable microstrip filters can be greatly improved using patterned ferroelectric thin films as the tuning element, and tuning can be controlled by engineering the ferroelectric constriction in the coupled sections.
\end{abstract}

\section{INTRODUCTION}

Ferroelectric thin films have been investigated aggressively during the past decade in an attempt to create compact, electronically tunable microwave components for communication applications [1-4]. Interdigital capacitors using ferroelectric thin films have displayed tunabilities of up to $70 \%$ at $1 \mathrm{MHz}[5,6]$ and proof-of-concept phase shifters have been demonstrated at frequencies up to $30 \mathrm{GHz}$ [7-9]. We have learned many things from these efforts. For example, epitaxial films tend to exhibit the higher relative dielectric constants $\left(\varepsilon_{\mathrm{r}}\right)$ than polycrystalline films. We also have learned that film strain is detrimental to the tuning-to-loss figure of merit. Nevertheless, one aspect that is still challenging the imaginations of microwave engineers as well as material scientists alike is how to preserve the tunability of these films while minimizing RF losses. Although losses are still a major concern, it is evident that the attainment of the aforementioned goal is closely related to the particular circuit design under consideration. 
Development of miniaturized, tunable narrowband ferroelectric bandpass filters for X-band ( 8 to $12 \mathrm{GHz}$ ) and higher frequency applications is appealing for several reasons. First, miniaturization of the filters is one of the key bottlenecks which delay advances in frequency-selective receiver functions [10]. Conventional passive distributedelement filters consume excessive space, whereas lumped-element filters introduce excessive transmission losses. Another problem which plagues miniaturized filter development is the difficulty of maintaining the production and accuracy standards necessary to develop filters. Microstrip coupled filters require dimensional standards that are difficult to meet in a production environment. The lack of a highly advanced means of introducing miniaturized, tunable filters into signal processing circuitry significantly hinders our ability to make use of available semiconductor materials.

Implementation of ferroelectric materials into narrowband filters has been difficult for several reasons. First, the losses in ferroelectric films used for microwave tuning applications are too high to be realistically considered in most filter applications. Narrowband filters create an especially difficult challenge for ferroelectric thin films, since coupled elements tend to be spaced far apart, thus creating a large ferroelectric area over which the signal must propagate as well as raising the voltage levels that must be applied in order to reach electric fields capable of tuning the ferroelectric.

In this paper, we describe a promising method of maintaining circuit tunability while reducing the losses. The basic premise of the work is that patterning highly constricted regions in the ferroelectric layer will reduce the displacement current between the coupled sections. Since the electric fields are concentrated in the constricted regions, this approach also enables non-uniform tuning (i.e., high tuning in the constricted region, low tuning away from it) of the ferroelectric layer. The circuit used to test our hypotheses is a one-pole bandpass filter. The results obtained so far will be discussed.

\section{EXPERIMENTAL}

The filters used in this study were designed for a center frequency of $7.4 \mathrm{GHz}$. Modeling of these filters was performed using Sonnet's em software. Note however, that currently available electromagnetic simulators have difficulty modeling the non-uniform field distributions induced by the presence of the ferroelectric in areas adjacent to the transmission lines. Thus, empirical demonstrations are required to determine the effectiveness of the approach considered in this paper as well as any other approach dealing with thin film ferroelectric based structures. Figure 1, shows a schematic of the filter structure used in the current study. Note that the ferroelectric film does not cover the entire area within the microstrips, as in typical microstrip design. Instead, its dimensions were varied (see Table I) so as to identify the parameters that most significantly impact on the overall filter performance. Note that the ferroelectric has a middle constriction that concentrates the electric field in the constricted area. Thus, the idea here is to determine if by following this approach we can preserve or enhance tunability and reduce losses.

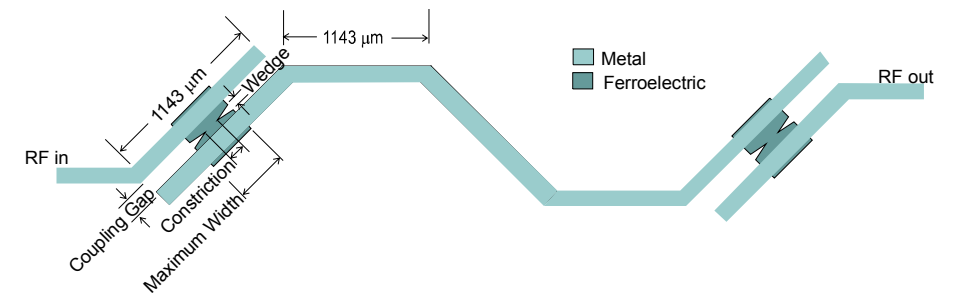

Figure 1: One-Pole Microstrip Filter with Etched Ferroelectric Layer

Table I: Variable Parameters for One-Pole Filter

\begin{tabular}{|c|c|c|}
\hline $\begin{array}{c}\text { Sample } \\
\text { Number }\end{array}$ & $\begin{array}{c}\text { Maximum } \\
\text { Width }(\mu \mathrm{m})\end{array}$ & $\begin{array}{c}\text { Constriction } \\
(\mu \mathrm{m})\end{array}$ \\
\hline A2 & 762 & 50.8 \\
\hline B2 & 508 & 50.8 \\
\hline C1 & 254 & 25.4 \\
\hline C2 & 254 & 50.8 \\
\hline C10 & 254 & 254 \\
\hline
\end{tabular}


The filter used in this study was designed for a center frequency of $7.4 \mathrm{GHz}$ (without ferroelectric) on a $254 \mu \mathrm{m}$ thick lanthanum aluminate $\left(\mathrm{LaAlO}_{3}\right.$ henceforth $\left.\mathrm{LAO}\right)$ substrate. In the ferroelectric version, the coupled microstrip line has a selectively etched $\mathrm{Ba}_{0.50} \mathrm{Sr}_{0.50} \mathrm{TiO}_{3}$ (BSTO) ferroelectric thin film layer of $0.4 \mu \mathrm{m}$ thickness grown on the LAO substrate by pulsed laser deposition. Standard positive photolithography and wet etching techniques were used to selectively etch the BSTO films. The BSTO was selectively etched in a 1:20 Hydrofluoric acid:DI $\mathrm{H}_{2} \mathrm{O}$ solution, and the etch rate was approximately $30 \mathrm{~nm} / \mathrm{min}$. The etched ferroelectric layer is shown in figure 2. A lift-off photolithographic process was used for the fabrication of the gold filters. A gold layer $\sim 2 \mu \mathrm{m}$ was deposited for the ground plane to complete the circuit fabrication.

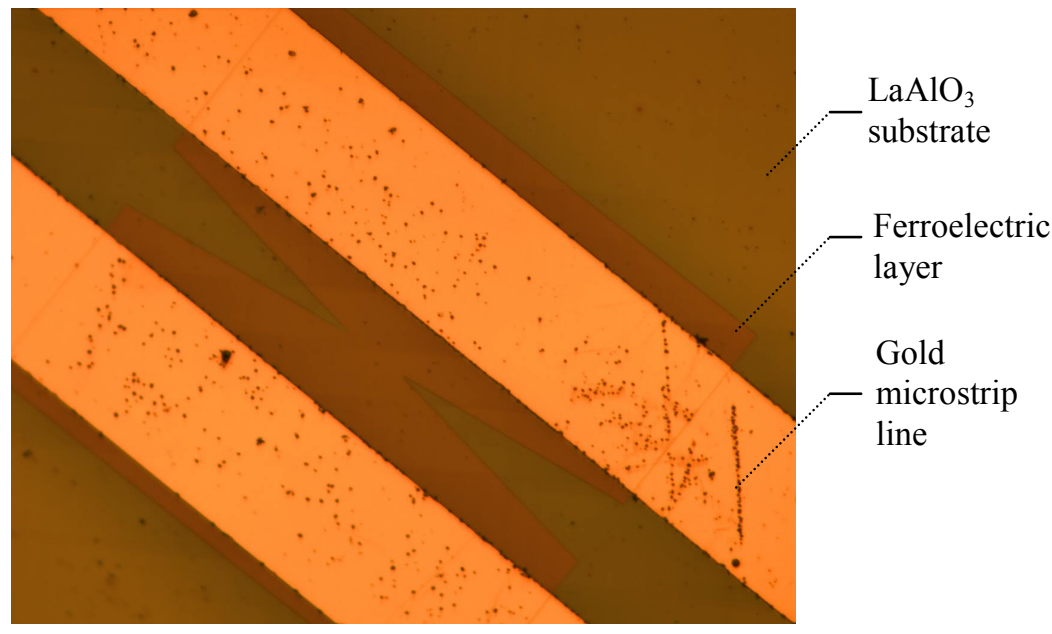

Figure 2. Coupled section of filter, showing etched ferroelectric layer.

For RF characterization the filters were tested inside a vacuum chamber to allow for high voltage biasing of the resonator. Voltages up to \pm 400 volts dc could be applied for testing this filter. Since the width of the coupled gaps was $114 \mu \mathrm{m}$, the maximum electric field was 3.5 volts $/ \mu \mathrm{m}$. The transmission and reflection scattering parameters $\left(\mathrm{S}_{21}\right.$ and $\mathrm{S}_{11}$, respectively) were measured at room temperature using an HP 8510C network analyzer.

\section{RESULTS}

Figure 3.a shows $\mathrm{S}_{21}$ data for sample A2 (see Table I), over the frequency range 4 to $24 \mathrm{GHz}$. Note that the fundamental resonance of the filter at no bias is $7.27 \mathrm{GHz}$, but is lower than the design frequency due to the higher effective dielectric constant $\left(\varepsilon_{\text {eff }}\right)$ resulting from the ferroelectric film. The first and second harmonics of the filter are clearly visible. Upon application of dc voltage (with the input and output microstrip lines kept at ground and the resonator positively biased), the filter exhibited a frequency tuning of $528 \mathrm{MHz}$ at a center frequency of $\sim 21 \mathrm{GHz}$. The insertion loss at zero bias field was $4.2 \mathrm{~dB}$, and dropped to $2.8 \mathrm{~dB}$ when biased to 400 volts. Figure $3 . \mathrm{b}$ shows the $S_{11}$ corresponding to the first harmonic of this filter. To isolate the mechanism(s) responsible for the loss and tuning characteristics, filters in which either a) the maximum width of the dielectric brick at the metal/dielectric interface; or b) the constriction of the ferroelectric block within the coupled section, were varied. 


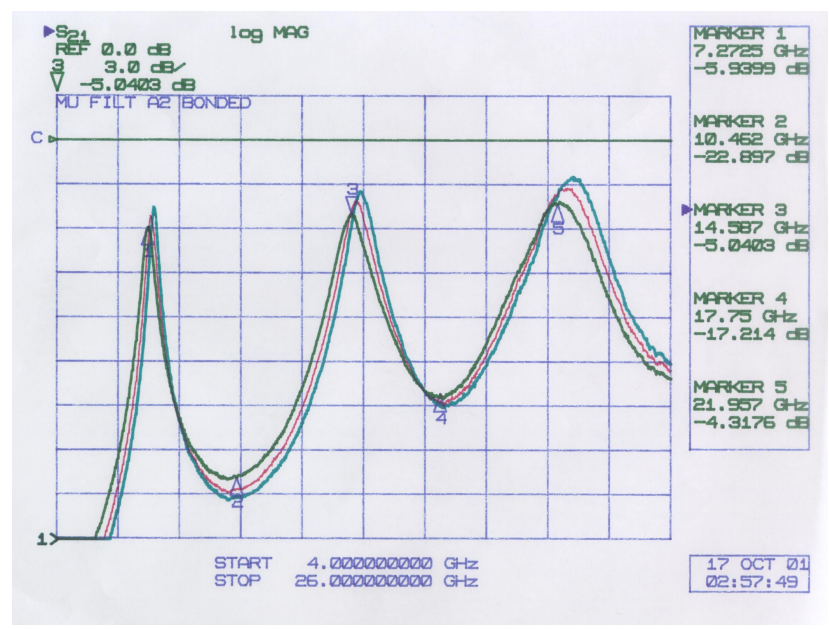

Figure 3.a. Transmission $\left(\mathrm{S}_{21}\right)$ versus frequency for filter $\mathrm{A}$, at bias levels of 0,200 , and 400 volts.

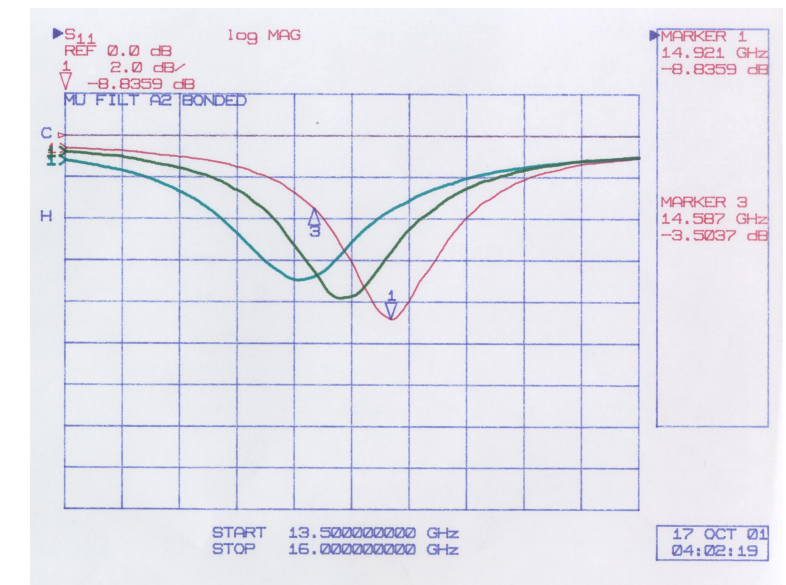

Figure 3.b. Reflection $\left(\mathrm{S}_{11}\right)$ versus frequency or filter $\mathrm{A} 2$, at bias levels of 0,200 , and 400 volts.

Figure 4 demonstrates the effect of reducing the maximum width of the ferroelectric (sample B2). Comparing A2 and B2, there was very little difference in microwave tuning or insertion loss for the fundamental resonance or first harmonic by reducing the width of the ferroelectric block from 762 to $508 \mu \mathrm{m}$, but maintaining the constriction at 51 $\mu \mathrm{m}$. There is some degradation in the second harmonic, probably due to the diminished electromagnetic coupling at those frequencies. The effect of further decreasing the maximum width of the patterned brick to $254 \mu \mathrm{m}$, while maintaining the constriction at $51 \mu \mathrm{m}$, is demonstrated in figures 5.a and 5.b (sample C2). Once again, the frequency and tunability for the fundamental and first harmonic peaks are similar to those of the A2 and B2 filters. It appears that the maximum width of the patterned ferroelectric layer had little impact on the tunability and resonant frequency. At frequencies above the first harmonic, the shape of resonance was much better defined for the A2 sample than that of the $\mathrm{B} 2$ or $\mathrm{C} 2$ samples. 


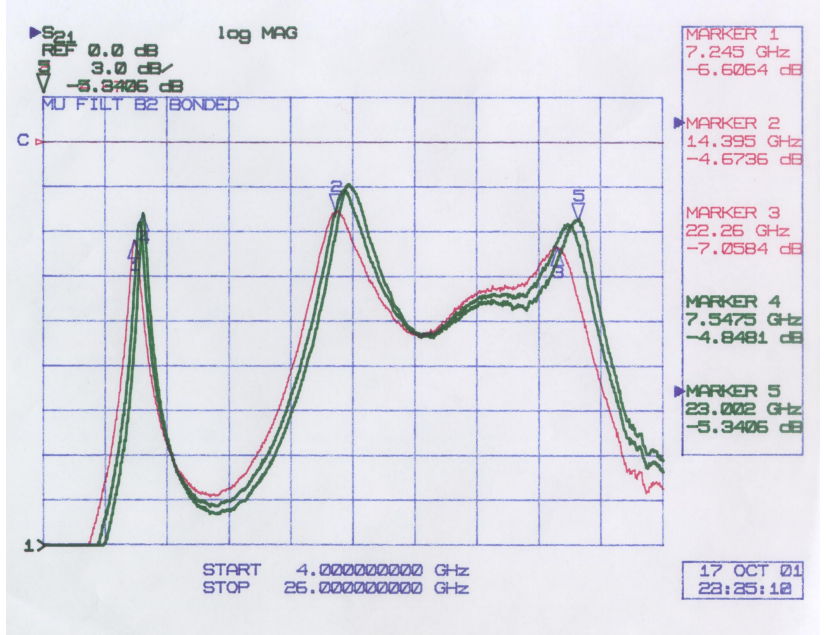

Figure 4. Transmission $\left(S_{21}\right)$ versus frequency for filter B2, at bias levels of $0,100,200,300$ and 400 volts.

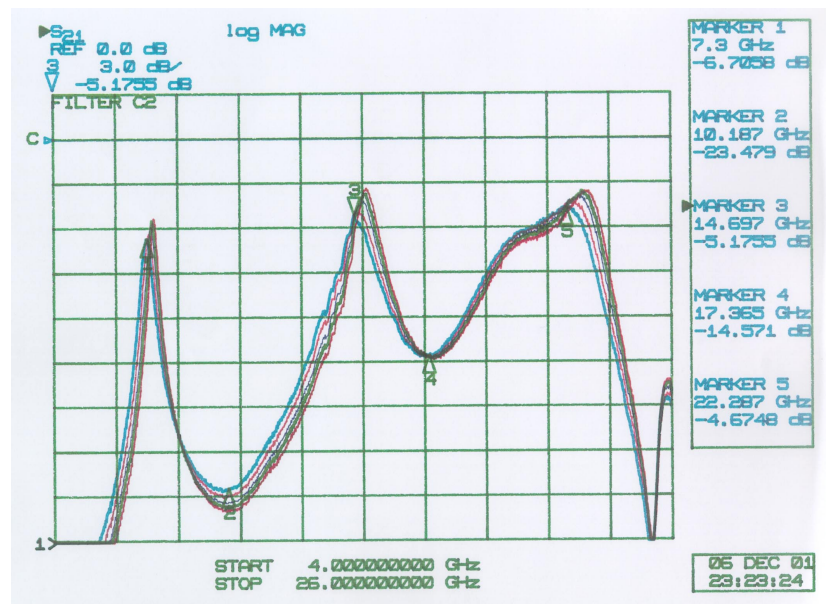

Figure 5.a. Transmission $\left(\mathrm{S}_{21}\right)$ versus frequency for filter $\mathrm{C} 2$, at bias levels of $0,100,200,300$ and 400 volts.

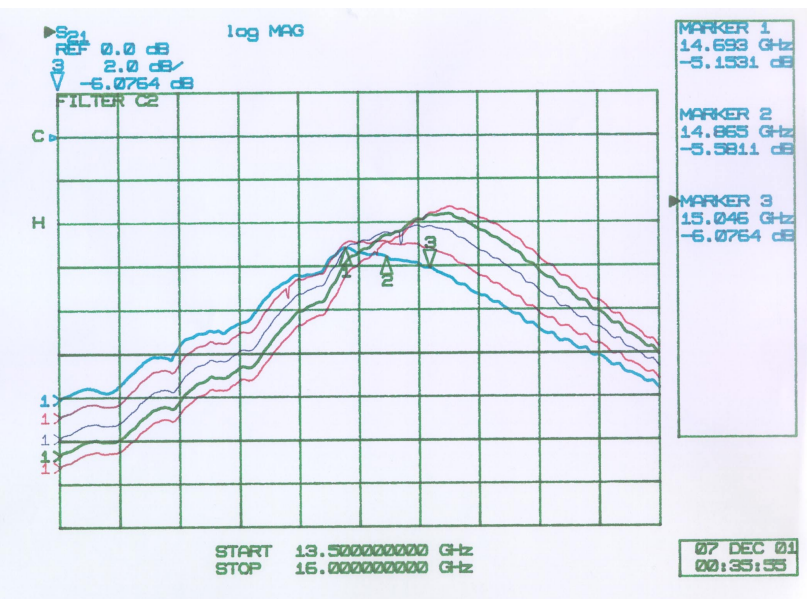

Figure 5.b. Transmission $\left(\mathrm{S}_{21}\right)$ versus frequency for filter $\mathrm{C} 2$, at bias levels of $0,100,200,300$ and 400 volts. 
To investigate the manner in which the constriction affects filter performance, the maximum width of the patterned section (at the ferroelectric/microstrip interface) was held constant at $204 \mu \mathrm{m}$, and the constriction was either reduced to $25 \mu \mathrm{m}$ (sample C1), or increased to $254 \mu \mathrm{m}$ (C10). Since the maximum width and constriction of $\mathrm{C} 1$ and $\mathrm{C} 10$ were both $254 \mu \mathrm{m}$, there was no constriction in this sample. Although not shown in this paper, the microwave performance of $\mathrm{C} 1$ closely resembled that of $\mathrm{C} 2$, except the insertion losses were slightly higher. For example, the $0 \mathrm{~V}$ insertion loss of the first harmonic peak $(14.587 \mathrm{GHz})$ of $\mathrm{C} 1$ was $5.8 \mathrm{~dB}$, and dropped to $4.2 \mathrm{~dB}$ with a $400 \mathrm{~V}$ bias. The resonant frequency was tunable by $320 \mathrm{MHz}$. By contrast, the $0 \mathrm{~V}$ insertion loss of the first harmonic peak $(14.697 \mathrm{GHz}$ ) of $\mathrm{C} 2$ was $5.1 \mathrm{~dB}$, and dropped to $3.2 \mathrm{~dB}$ with a 400 volt bias. The resonant frequency was tunable by $457 \mathrm{MHz}$.

To further demonstrate the importance of the constriction, a filter with a $254 \mu \mathrm{m}$ brick and no constriction (C10) was fabricated. The performance of this filter is displayed in figures 6.a and 6.b. This filter was markedly inferior to that of any of the filters with constricted ferroelectric layers. The insertion loss of the first harmonic peak $(14.917 \mathrm{GHz})$ was $8.5 \mathrm{~dB}$, and dropped to $6.5 \mathrm{~dB}$ with a $400 \mathrm{~V}$ bias. The resonant frequency was tunable by $180 \mathrm{MHz}$. The performance degradation was even more apparent in the fundamental resonance, where the $0 \mathrm{~V}$ insertion loss was $15.56 \mathrm{~dB}$. The $0 \mathrm{~V}$ and $400 \mathrm{~V}$ insertion losses of the second harmonic were 6.8 and $5.3 \mathrm{~dB}$, respectively.

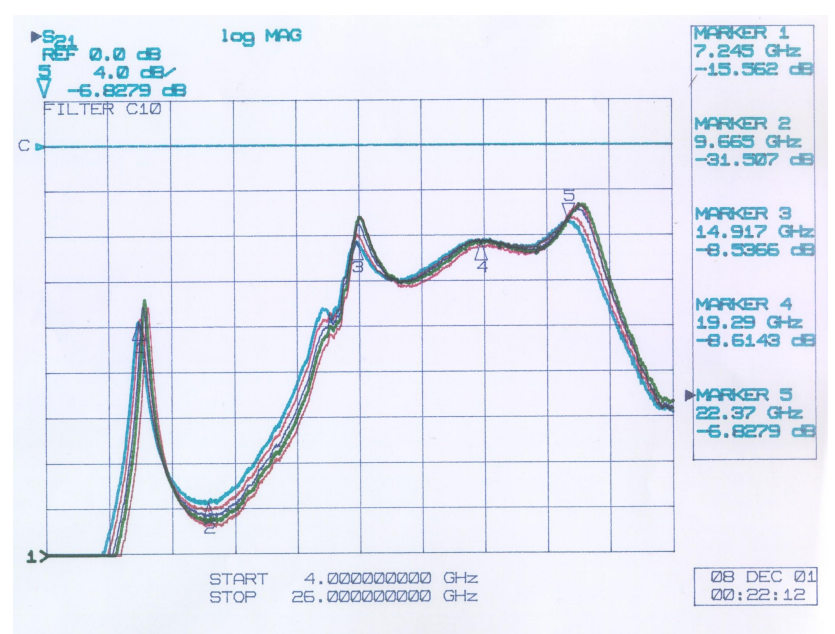

Figure 6.a. Transmission $\left(\mathrm{S}_{21}\right)$ versus frequency for filter $\mathrm{C} 10$, at bias levels of $0,100,200,300$ and 400 volts.

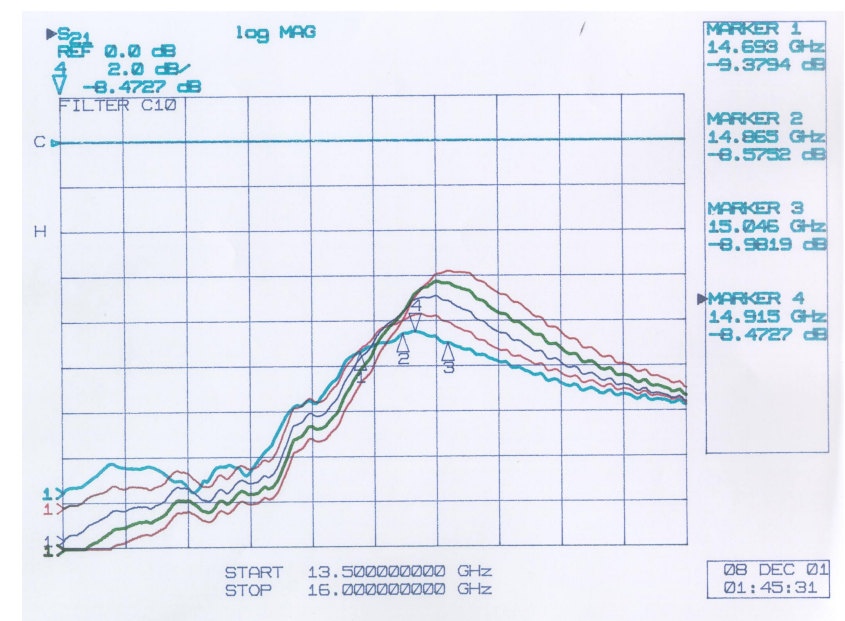

Figure 6.b. Transmission $\left(\mathrm{S}_{21}\right)$ versus frequency for filter $\mathrm{C} 10$, at bias levels of $0,100,200,300$ and 400 volts. 


\section{DISCUSSION}

This study confirms that the most significant parameter affecting the tunability and loss of the filters is the constriction. The maximum width of the patterned ferroelectric had little impact on the resonant frequency of the fundamental or the first two overtones, or the tunability of each of these resonances. However, it appeared to have a substantial impact on the shape of the highest frequency $(\sim 21 \mathrm{GHz})$ resonance. The shape as well as the performance of the second harmonic of sample A2 was clearly superior to those with narrower widths at the electrode/ferroelectric junction, but identical constrictions (B2 and $\mathrm{C} 2$ ). Clearly, the constriction dramatically improved the microwave performance of the filter, and we believe the primary mechanism by which this performance enhancement is brought about is concentration of the electric field at the constricted region, thus creating a low $\varepsilon_{\mathrm{r}}$ region in the constricted region. Since this region is electrically connected in series with the surrounding high $\varepsilon_{\mathrm{r}}$ portion of the film (i.e. area outside of the constricted region), the effective dielectric constant and loss of the coupled region is substantially reduced.

Comparing samples $\mathrm{C} 2$ and $\mathrm{C} 1$, relatively minor changes were observed in tunability or insertion loss by decreasing the constriction from 51 to $25 \mu \mathrm{m}$. It appears that for the filter design and ferroelectric patterning structure used in this set of experiments, the effect of the constriction on concentrating the electric fields and enhancing tunability is already maximized for the $51 \mu \mathrm{m}$ constriction, and further reductions have a slightly deleterious effect.

Comparing samples $\mathrm{C} 2$ and $\mathrm{C} 10$ provides substantive evidence that the constriction was the key parameter that controlled tuning and insertion loss. Eliminating the constriction resulted in a very large drop in resonator performance for all three resonances, but the performance drop was particularly clear for the fundamental and first harmonic. The first harmonic insertion loss at $0 \mathrm{~V}$ bias was over $2.5 \mathrm{~dB}$ worse than any of the filters that had a constricted ferroelectric layer. Furthermore, the tunability was less than $200 \mathrm{MHz}$. By contrast, the constricted filters displayed $320(\mathrm{C} 1)$ and 457 (C2) MHz of tuning.

\section{CONCLUSIONS}

We have demonstrated that patterned ferroelectric filters have much better RF performance than unpatterned filters. The parameter responsible for the performance enhancement was the constriction, and we believe the constriction concentrates the electric fields in a narrow region within the coupled section.

\section{REFERENCES}

[1] G. Subramanyam, F.W. Van Keuls, F.A. Miranda, IEEE Trans. Microwave Theory and Tech., 48, p. 525 (2000).

[2] G. Subramanyam, N. Mohsina, A. Zaman, F.W. Van Keuls, F.A. Miranda, R. Romanofsky, J.D. Warner, and C. Chen, Integrated Ferroelectrics 42, p. 151(2002).

[3] F.A. Miranda, G. Subramanyam, F.W. Van Keuls, R.R. Romanofsky, J.D. Warner, and C.H. Mueller, IEEE Trans. Microwave Theory and Tech., 48, p. 1 (2000).

[4] C.H. Mueller and F.A. Miranda "Tunable Dielectric Materials and Devices for Broadband Wireless Communications," in Handbook of Thin Film Devices, Volume 5: Ferroelectric Film Devices. Edited by D.J. Taylor and M.H. Francombe, p. 113-140 (Academic Press, New York, 2000).

[5] A. Findikoglu, Q. Jia, I. Campbell, X. Wu, D. Reagor, C. Mombourquette, and D. McMurry, Appl. Phys. Lett. 66, p. 3675 (1995).

[6] R. Treece, J. Thompson, C. Mueller, T. Rivkin, and M. Cromar, IEEE Trans. Appl. Supercond., 7, p. 2363 (1997).

[7] F.W. Van Keuls, R.R. Romanofsky, D.Y. Bohman, M.D. Winters, F.A. Miranda, C.H. Mueller, R.E. Treece, T.V. Rivkin, and D. Galt, Appl. Phys. Lett., 71, p. 3075 (1997).

[8] A.B. Kozyrev, T.B. Samoilova, A.A. Golovkov, E.K. Hollmann, D.A. Kalinikos, V.E. Loginov, A.M. Prudan, O.I. Soldatenkov, D. Galt, C.H. Mueller, T.V. Rivkin, and G.A. Koepf, J. Appl. Phys., 84, p. 3326 (1998).

[9] Y. Liu, B. Acikel, A.S. Nagra, T.R. Taylor, P.J. Hansen, J.S. Speck, and R.A. York, Integrated Ferroelectrics 39, p. 313 (2001).

[10] C. Rauscher, IEEE Microwave Theory and Techn. Symp. Digest p. 605 (1994). 
Public reporting burden for this collection of information is estimated to average 1 hour per response, including the time for reviewing instructions, searching existing data sources, gathering and maintaining the data needed, and completing and reviewing the collection of information. Send comments regarding this burden estimate or any other aspect of this collection of information, including suggestions for reducing this burden, to Washington Headquarters Services, Directorate for Information Operations and Reports, 1215 Jefferson Davis Highway, Suite 1204, Arlington, VA 22202-4302, and to the Office of Management and Budget, Paperwork Reduction Project (0704-0188), Washington, DC 20503.

\begin{tabular}{|l|l|l|}
\hline 1. AGENCY USE ONLY (Leave blank) & $\begin{array}{c}\text { 2. REPORT DATE } \\
\text { January } 2003\end{array}$ & $\begin{array}{r}\text { 3. REPORT TYPE AND DATES COVERED } \\
\text { Technical Memorandum }\end{array}$ \\
\hline
\end{tabular}

\section{TITLE AND SUBTITLE}

5. FUNDING NUMBERS

Performance Enhancement of Tunable Bandpass Filters Using Selective Etched Ferroelectric Thin Films

\section{AUTHOR(S)}

Félix A. Miranda, Carl H. Mueller, Fred W. Van Keuls, Guru Subramanyam, and Sivaruban Vignesparamoorthy

\section{PERFORMING ORGANIZATION NAME(S) AND ADDRESS(ES)}

National Aeronautics and Space Administration

John H. Glenn Research Center at Lewis Field

Cleveland, Ohio 44135-3191
WBS-22-755-08-02

\section{SPONSORING/MONITORING AGENCY NAME(S) AND ADDRESS(ES)}

National Aeronautics and Space Administration

Washington, DC 20546-0001
8. PERFORMING ORGANIZATION REPORT NUMBER

E-13423

\section{SUPPLEMENTARY NOTES}

Prepared for the 13th International Symposium on the Applications of Ferroelectrics sponsored by the Ultrasonics, Ferroelectrics, and Frequency Control Society, Nara, Japan, May 28-June 1, 2002. Félix A. Miranda, NASA Glenn Research Center; Carl H. Mueller, Analex Corporation, Brook Park, Ohio 44142; Fred W. Van Keuls, Ohio Aerospace Institute, Brook Park, Ohio 44142; and Guru Subramanyam and Sivaruban Vignesparamoorthy, University of Dayton, Dayton, Ohio 45458. Responsible person, Félix A. Miranda, organization code 5640, 216-433-6589.

12a. DISTRIBUTION/AVAILABILITY STATEMENT

Unclassified - Unlimited

Subject Categories: 04, 17, and 32

Distribution: Nonstandard

Available electronically at http://gltrs.grc.nasa.gov

This publication is available from the NASA Center for AeroSpace Information, 301-621-0390.

\section{ABSTRACT (Maximum 200 words)}

The inclusion of voltage-tunable barium strontium titanate (BSTO) thin films into planar band pass filters offers tremendous potential to increase their versatility. The ability to tune the passband so as to correct for minor deviations in manufacturing tolerances, or to completely reconfigure the operating frequencies of a microwave communication system, are highly sought-after goals. However, use of ferroelectric films in these devices results in higher dielectric losses, which in turn increase the insertion loss and decrease the quality factors of the filters. This study explores the use of patterned ferroelectric layers to minimize dielectric losses without degrading tunability. Patterning the ferroelectric layers enables us to constrict the width of the ferroelectric layers between the coupled microstrip lines, and minimize losses due to ferroelectric layers. Coupled one-pole microstrip bandpass filters with fundamental resonances at $\sim 7.2 \mathrm{GHz}$ and welldefined harmonic resonances at $\sim 14.4$ and $\sim 21.6 \mathrm{GHz}$, were designed, simulated and tested. For one of the filters, experimental results verified that its center frequency was tunable by $528 \mathrm{MHz}$ at a center frequency of $21.957 \mathrm{GHz}$, with insertion losses varying from 4.3 to $2.5 \mathrm{~dB}$, at 0 and $3.5 \mathrm{~V} / \mu \mathrm{m}$, respectively. These data demonstrate that the tuning-toloss figure of merit of tunable microstrip filters can be greatly improved using patterned ferroelectric thin films as the tuning element, and tuning can be controlled by engineering the ferroelectric constriction in the coupled sections.

14. SUBJECT TERMS

Ferroelectric; Microwave; Filter; Tunable; BSTO; Selective etching; Insertion loss 15. NUMBER OF PAGES

\begin{tabular}{|c|c|c|}
\hline $\begin{array}{c}\text { 17. SECURITY CLASSIFICATION } \\
\text { OF REPORT } \\
\text { Unclassified }\end{array}$ & $\begin{array}{c}\text { 18. SECURITY CLASSIFICATION } \\
\text { OF THIS PAGE } \\
\text { Unclassified }\end{array}$ & $\begin{array}{c}\text { 19. SECURITY CLASSIFICATION } \\
\text { OF ABSTRACT } \\
\text { Unclassified }\end{array}$ \\
\hline
\end{tabular}

